PALABRAS CLAVE

Bancos

Sistemas bancarios

Operaciones bancarias

Crédito

Desarrollo económico

Análisis de datos

Indicadores económicos

Brasil

Daniel B. de Castro Almeida

Economista,

Banco de Desarrollo de Minas Gerais

(BDMG)

danielb@bdmg.mg.gov.br

Frederico G. Jayme Jr.

Profesor de la Facultad de Economía

y del Centro de Desarrollo y

Planeamiento Regional (CEDEPLAR),

Universidad Federal de Minas Gerais

(UFMG)

gonzaga@cedeplar.ufmg.br
REVISTA DE LA CEPAL 95 AGOSTO 2008

\section{Consolidación bancaria y concentración del crédito en Brasil (1995-2004)}

\author{
Daniel B. de Castro Almeida y Frederico G. Jayme Jr.
}

A partir de la estabilización monetaria de 1994, se aceleró la consolidación bancaria en Brasil, siguiendo una tendencia mundial a la concentración a partir de un proceso de desregulación de la banca. El presente trabajo analiza el efecto de la concentración bancaria en la concesión de crédito en Brasil en el período 1995-2004, distinguiendo en él dos etapas. Para llevar a cabo el análisis se realizó una estimación con datos en panel, utilizando información referente a las 27 unidades federales de Brasil. Los resultados corroboran la hipótesis de que el proceso de consolidación del sector bancario brasileño tiene un efecto negativo sobre la concesión de crédito, lo cual perjudica principalmente a las regiones menos desarrolladas del país. 


\section{I}

\section{Introducción}

A partir de la estabilización monetaria, el sistema bancario brasileño pasó por un acelerado proceso de consolidación, fenómeno que se enmarca en la tendencia mundial a la concentración de la banca, principalmente ante la mayor desregulación del sector. Desde el punto de vista teórico, existen dos corrientes contrapuestas para explicar el fenómeno. La primera sostiene que la consolidación es resultado de la mayor eficiencia de algunas instituciones frente a las demás, lo que lleva a la adquisición como forma de alcanzar ventajas de escala. Para este grupo, la consolidación beneficia a los consumidores, ya que está basada en la mayor eficiencia de las instituciones. La otra corriente argumenta que las adquisiciones y fusiones de bancos apuntan a obtener mayor poder de mercado, en detrimento de los consumidores, que tendrían que pagar más por los servicios bancarios.

En el caso de Brasil, la pérdida del beneficio que derivaba de la inflación ayudó a impulsar la consolidación del sector. Esta contó además con el apoyo oficial del Estado a través de mecanismos como el Programa de estímulo a la reestructuración y al fortalecimiento del sistema financiero nacional (PROER) y el Programa de estímulo a la reestructuración del sistema financiero estadual (PROES), ya que apuntaba a un sistema bancario menos vulnerable a perturbaciones (shocks). A partir de 1994 se observan en Brasil dos fenómenos: i) la concentración geográfica de las sucursales bancarias y ii) la reducción del número de bancos, resultante del proceso de fusiones y adquisiciones, así como de las liquidaciones, también con concentración regional.

No es este un proceso que pase inadvertido o que no tenga mayores repercusiones en la economía. En el ámbito internacional se dispone de diversos estudios que

$\square$ Los autores agradecen los valiosos comentarios de Clélio Campolina Diniz, Ana Maria Hermeto Oliveira y Luiz Fernando de Paula, así como la eficaz asistencia en la investigación de Ana Luíza Oliveira. Por su parte, Frederico G. Jayme Jr. agradece el financiamiento del Consejo Nacional de Desarrollo Científico y Tecnológico (CNPQ). procuran definir la relación existente entre el desarrollo financiero y el crecimiento económico (Levine, 1997; Matos, 2002). Asimismo, se esgrimen argumentos teóricos que apuntan a un efecto positivo e importante del desarrollo del sistema financiero en el crecimiento económico y hay evidencias de que ese desarrollo tiene efectos favorables en la tasa de crecimiento de la economía brasileña (Matos, 2002; Araújo y Dias, 2006).

El objetivo del presente trabajo es analizar el efecto que el proceso de concentración de la banca en Brasil ha tenido en la concesión de crédito. Para ello, además del análisis estadístico de los datos referentes al sector bancario y de un repaso de las publicaciones sobre el tema, se efectuó un análisis de datos en panel con valores correspondientes al período 1995-2004 para las 27 unidades federales, con el propósito de captar qué efectos tiene la dinámica de la concentración bancaria en el crédito, a nivel regional. Los resultados corroboran que la concentración bancaria en Brasil entre 1995 y el 2004 tuvo consecuencias adversas para el crédito. Se observa que la ausencia o merma del número de bancos y de sus sucursales da lugar a una reducción del crédito. Por falta de información, no ha sido posible analizar esto en los años posteriores al 2004, en los cuales aumentó en general el crédito en Brasil, aunque siguió estando muy por debajo del promedio internacional.

Este artículo consta de cinco secciones. A continuación, en la sección II se presenta un breve examen de estudios teóricos sobre la relación entre el sistema financiero y el desarrollo económico, así como una reseña del proceso de consolidación del sector bancario y de algunos factores que determinan las decisiones de otorgar crédito. En la sección III se analiza el caso de Brasil, el momento en que el proceso de concentración de la banca se hizo más evidente, las principales características del proceso y sus efectos en el crédito. En la sección IV se presentan los resultados empíricos del modelo propuesto. Por último, en la sección $\mathrm{V}$ se formulan algunas conclusiones. 


\section{II}

\section{El sistema bancario y el crédito: teoría y evidencia sobre el caso de Brasil}

Desde hace algún tiempo, el desarrollo financiero y su relación con el desarrollo económico despiertan el interés de varios autores. ${ }^{1}$ La cuestión es si el desarrollo económico da lugar al desarrollo financiero o si la relación de causalidad es inversa. No hay consenso en torno a este tema, e inclusive puede existir una doble causalidad. No obstante, sí hay acuerdo en que el crédito desempeña un papel crucial en el desarrollo económico.

Levine (1997) analiza los factores que propician el surgimiento y desarrollo del sistema financiero, así como su efecto en el desarrollo económico. Destaca que los costos de transacción, así como los de obtener la información, crean los incentivos necesarios para que surjan mercados e instituciones financieras. Estas instituciones tienen como funciones primordiales: i) facilitar las transacciones, protegerse del riesgo y diversificarlo; ii) asignar recursos; iii) supervisar a los administradores y ejercer un control corporativo; iv) movilizar el ahorro, y v) facilitar el intercambio de bienes y servicios.

A través de estas funciones y capacidades, el sistema financiero logra modificar la tasa de ahorro y reasignarla a diversos capitales, incidiendo en la acumulación de capital. Para viabilizar las funciones mencionadas, los bancos tienen que dar liquidez a los activos, además de proveer información (Neuberger, 1997). De esta definición se desprende que la incertidumbre asociada a la capacidad de conversión de los activos en medios de intercambio genera riesgo en materia de liquidez. ${ }^{2}$

Según Matos (2002), en el caso de Brasil hay pruebas de una relación positiva, causal y unidireccional entre el desarrollo financiero y el crecimiento económico. En otro estudio, Araújo y Dias (2006) dieron forma a

\footnotetext{
${ }^{1}$ Entre otros, Levine (1997), Rajan y Zingales (1998), Demetriades y Hussein (1996), Arestis y Demetriades (1997) y Jayaratne y Strahan (1996).

${ }^{2}$ Para Keynes (1992: p. 138), la preferencia por la liquidez es una potencialidad o tendencia funcional que fija la cantidad de moneda que el público retendrá cuando la tasa de interés sea dada”. Por otra parte, la condición necesaria sin la cual no existiría la preferencia por la liquidez como medio de preservación de la riqueza es la existencia de incertidumbre en cuanto al futuro de la tasa de interés. Así, en períodos de mayor incertidumbre, el premio a los activos relativamente más líquidos aumentará en relación con aquel a los activos menos líquidos.
}

un modelo en el cual el crecimiento de la economía es función del acervo de capital y de variables monetarias como las reservas bancarias. Las alzas de la tasa de interés y del impuesto inflación inciden negativamente, pero sin efectos permanentes, en la tasa de crecimiento del PIB. Por otro lado, el aumento de las reservas bancarias determina reducciones permanentes de la tasa de crecimiento de la economía. En otras palabras, el acervo de reservas bancarias, determinado sobre la base de la regulación de la autoridad monetaria y las expectativas de los agentes financieros, incide en forma permanente en la tasa de crecimiento de la economía.

Al generar la demanda de depósitos y elegir una combinación adecuada de inversiones, los bancos ofrecen a los ahorristas un clima de seguridad frente a los riesgos de liquidez, en tanto que, simultáneamente, facilitan las inversiones de largo plazo en proyectos de mayor rentabilidad. Además, hacen una importante contribución al buen funcionamiento de la economía. Por otro lado, el proceso de concentración afecta directamente al crédito, particularmente en las regiones menos desarrolladas. Para esto hay dos explicaciones: i) la hipótesis estructural postula que las fusiones y adquisiciones están motivadas por el deseo del adquirente de obtener poder de mercado $\mathrm{y}$, de esa manera, incrementar sus márgenes de utilidades, y ii) la hipótesis de la eficiencia sugiere que, en un ambiente de competencia, las empresas que consiguen reducir sus costos y obtener mayor rentabilidad ganan mercado y, por ende, escala de producción, por lo que terminan comprando las empresas menos eficientes para inyectarles mejores prácticas de gestión y acrecentar así sus propias ganancias.

En lo que hace a la concentración, De Paula y Marques (2004) enumeran los factores que la impulsan en el ámbito mundial: i) la desregulación de los servicios financieros, ii) la mayor apertura del sector bancario a la competencia internacional, iii) los avances tecnológicos y iv) los cambios en la estrategia empresarial. Los bancos apuntarían a la consolidación porque con ella podrían lograr economías de escala y de alcance, elevar su rentabilidad y acrecentar su poder monopolístico. Se estarían así mezclando los objetivos señalados en las dos hipótesis. 
En el debate sobre el grado de concentración del sistema bancario se busca un punto de equilibrio entre la estabilidad del sistema y la competitividad. Cuanto mayor sea la concentración, más grandes serán los bancos y más diversificadas sus actividades y, por consiguiente, mayor será la estabilidad y menor la fragilidad del sistema bancario en caso de crisis (Beck, Demirgüç-Kunt y Levine, 2006, p. 1584). Además, una mayor concentración puede aumentar el poder de mercado de los bancos impulsando así sus utilidades. Finalmente, si el número de bancos decrece la fiscalización del sistema se torna más sencilla. Una mayor concentración del mercado facilita la tarea de supervisión y fiscalización del sistema, y se espera que la menor competencia, derivada de la concentración, disminuya el riesgo de quiebras bancarias y de crisis del sistema financiero.

El proceso de consolidación bancaria influye en el otorgamiento de crédito, pero no es el único factor. En pocas palabras, se puede decir que el banco gestiona sus activos de modo de configurar la mejor cartera de valores posible dentro de sus expectativas, tanto para la economía como para la rentabilidad de los activos, buscando equilibrar liquidez y rentabilidad (De Paula y Alves Jr., 2003; Baum, Caglayan y Ozkan, 2004; Blum y Nakane, 2005). Según el análisis de Keynes (1992), el comportamiento convencional tiene un importante papel en la formación de expectativas.
Sin embargo, cuanto mayor y más permanente es el crecimiento económico, más frágil tiende a ser el sistema financiero ante las crisis, como lo subrayó Minsky (1986). Los bancos, como todo agente económico, prefieren la liquidez, lo que se acentúa cuanto más incierto es el futuro. ${ }^{3}$ De esta manera, cuando la economía está creciendo, las expectativas se tornan cada vez más positivas y los bancos empiezan a adoptar posturas más osadas en la concesión de crédito, reduciendo las exigencias para otorgar los préstamos y concediendo créditos más riesgosos.

Más allá de los efectos de la coyuntura económica en el crédito y del análisis que hacen los bancos respecto a clientes y proyectos, no se pueden dejar de lado el efecto del marco regulador en el crédito, ni las exigencias de capital para los bancos que operan en el mercado brasileño, fruto de la adopción del Acuerdo de Basilea.

De todos modos, queda en evidencia el efecto positivo del crédito en la economía, lo que acrecienta la importancia de analizar las consecuencias de la concentración bancaria en el crédito. La banca representa en Brasil casi $96 \%$ del sistema financiero, pese a que la razón crédito/PIB es inferior a la de otros países. Esto último refleja las posibilidades de crecimiento que el crédito tiene en el país en su conjunto (IPEA, 2006). Según Meirelles (2006), la relación crédito/PIB en Brasil es de aproximadamente $30 \%$, mientras que en Chile es de $60 \%$ y en Alemania supera el $100 \%$.

\section{III \\ Consolidación y concentración bancaria en Brasil}

El proceso de consolidación de la banca en Brasil, que se aceleró a mediados de los años 1990, partió en 1988, cuando el Consejo Monetario Nacional creó la figura del banco múltiple. Asimismo, después de la estabilización de 1994 y de la desregulación del sector, el proceso de consolidación fue impulsado por factores adicionales a los señalados para la concentración bancaria. Esos factores adicionales fueron el proceso de estabilización de precios, el programa de privatización de los bancos estaduales y la adhesión al Acuerdo de Basilea.

En la concentración bancaria de Brasil se observan dos fenómenos simultáneos: la concentración geográfica de las sucursales bancarias y una gran cantidad de fusiones, adquisiciones y liquidaciones.
El primer fenómeno está relacionado con directrices emanadas de las autoridades monetarias y que fueron modificadas en años más recientes, en especial a inicios de la década de 1990. A comienzos de los años 1980, el Banco Central del Brasil tenía como meta extender los servicios bancarios a todos los municipios del país, mejorar estos servicios en los municipios menos socorridos y adoptar medidas de regionalización bancaria. Esta política fue abandonada y, dado que los bancos tuvieron que disminuir sus costos tras la desaparición

\footnotetext{
${ }^{3}$ Nótese que el concepto de preferencia por la liquidez como defensa contra la incertidumbre difiere teóricamente del concepto de asimetría de la información de Stiglitz y Weiss (1981).
} 
del beneficio inflacionario, se inició la reubicación de sucursales. ${ }^{4}$

Asimismo, en los años 1980 el sistema bancario vivió dos procesos que moldearon significativamente su estructura y sirvieron de motivación para el fenómeno de las fusiones y adquisiciones: el uso de los bancos públicos estaduales en el refinanciamiento de las deudas de las unidades federales y el proceso inflacionario (Corrêa, 2006).

En cuanto al proceso inflacionario, el Plan Real extinguió la principal fuente de rentabilidad del sistema bancario de la época: la flotación de la moneda. La estabilización impuso al sistema bancario la necesidad de racionalizar los costos, cerrar sucursales, despedir funcionarios e invertir más en automatización (Corrêa, 2006; Vilhena y Sicsú, 2006). Junto con la pérdida de los ingresos por inflación, los bancos públicos estaduales enfrentaron problemas de gestión. Estos cambios en el ambiente económico del sector bancario brasileño, unidos al proceso de consolidación que ya se registraba en el mundo, dieron pie a una profunda reestructuración del sistema. En el mismo período, Brasil suscribió el Acuerdo de Basilea, que apuntaba a dar mayor solidez al sector financiero y, en el contexto de una posible crisis bancaria, el objetivo perseguido fue la solidez del sector bancario.

Esta reestructuración fue impulsada por el PROER y el PROES, ${ }^{5}$ establecidos en 1995 y 1996, respectivamente,

\footnotetext{
${ }^{4}$ Actualmente, para brindar atención bancaria en regiones menos desarrolladas, los bancos recurren a los servicios de otras instituciones, como las casas de lotería y las agencias de correos, en el contexto de un fenómeno conocido como bancarización. Por resolución 2707, el Banco Central del Brasil autorizó a los bancos múltiples con cartera comercial, a los bancos comerciales y a la Caja Económica Federal a contratar empresas que se desempeñaran como corresponsales para prestar los servicios siguientes: recepción y trámite de propuestas de apertura de cuentas de depósitos a la vista, a plazo y de ahorro; recepción y pagos relativos a cuentas de depósitos a la vista, a plazo y de ahorro, así como aplicaciones y rescates en fondos de inversión; recepción y pagos derivados de convenios de prestación de servicios suscritos por el contratante de acuerdo con la reglamentación vigente; ejecución activa o pasiva de órdenes de pago en nombre del contratante; recepción y trámite de pedidos de préstamo y de financiamiento; análisis del crédito y registro de bienes; ejecución de cobro de títulos; otros servicios de control, incluido el procesamiento de datos y de las operaciones pactadas, así como otras actividades, a juicio del Banco Central del Brasil.

${ }^{5}$ Las principales disposiciones del PROES eran las siguientes: $i$ ) $100 \%$ de los recursos necesarios para sanear los bancos estaduales fueron condicionados a la privatización de las instituciones o a su transformación en organismos de fomento, o a su liquidación; ii) la ayuda federal quedaría limitada al $50 \%$ de los recursos necesarios en caso de que no hubiera transferencia del control accionario o transformación en organismos de fomento (el otro $50 \%$ quedaría a cargo de los gobiernos estaduales); iii) las garantías presentadas por los estados, en caso de ayuda federal, deberían ser adecuadas al monto
}

y el Fondo de garantía crediticia (FGC) (Corrêa, 2006). Además, en el 2001 se creó el Programa de Fortalecimiento de las Instituciones Financieras Federales (PROEF), en virtud del cual la Tesorería Nacional asumió parte de las deudas de los cuatro bancos controlados por el gobierno federal: el Banco do Brasil, la Caja Económica Federal, el Banco da Amazônia (BASA) y el Banco do Nordeste (BNB). Asimismo, la Caja, el BASA y el BNB recibieron una inyección de recursos.

A comienzos de los años 1990, de las 27 unidades federales solo los estados de Tocantins y de Mato Grosso do Sul carecían de un banco comercial estadual. Es fácil identificar los efectos del PROES, del proceso de privatización y de las liquidaciones. En 2002, solo los estados de São Paulo, Sergipe, Rio Grande do Sul y Espírito Santo contaban todavía con un banco comercial bajo control público del propio estado. Además, el gobierno federal había asumido el control de los bancos de los estados de Ceará, Piauí y Santa Catarina con la intención de privatizarlos, lo que efectivamente se hizo en 2005 con el banco cearense (Freitas, 2005).

Por otra parte, diversos bancos de desarrollo estaduales dejaron de existir, algunos absorbidos por los bancos estaduales antes de la privatización, simplemente extinguidos o transformados en organismos de fomento. Algunos estados que no contaban con bancos de desarrollo crearon organismos de fomento con la intención de atenuar los efectos de la ausencia de bancos comerciales públicos en el otorgamiento de crédito y la adopción de políticas industriales y de desarrollo en la región. En el presente trabajo, sin embargo, solo se analiza el crédito concedido por los bancos múltiples con cartera comercial, los bancos comerciales y las cajas económicas. Esto sugiere que las actividades de los bancos y organismos de desarrollo deberían ser analizadas en el futuro.

Es importante observar lo sucedido con los bancos públicos en este proceso de reestructuración, después de que los bancos estaduales prácticamente dejaron de existir (cuadro 1). Nótese que la disminución del número total de bancos no tuvo un curso lineal. La reducción fue mucho mayor entre los bancos públicos (de cerca del 56\%) que entre los privados (de casi 29\%). Así, en el 2004 la participación de los bancos privados en el sistema bancario era superior a la de 1995 y la de los bancos privados extranjeros había subido casi 20 puntos

del préstamo; en caso de incumplimiento, los estados autorizaban el retiro por los acreedores de los montos correspondientes de sus cuentas bancarias de depósitos (De Paula y Marques, 2004, p. 15). 
Brasil: número de bancos, según la naturaleza del capital, a diciembre de cada año

\begin{tabular}{lrrrrrrrrrr}
\hline Bancos $^{\mathrm{a}}$ & 1995 & 1996 & 1997 & 1998 & 1999 & 2000 & 2001 & 2002 & 2003 & 2004 \\
\hline Públicos & 32 & 32 & 27 & 22 & 19 & 17 & 15 & 15 & 15 & 14 \\
Privados $^{\text {Nacionales }}{ }^{\mathrm{b}}$ & 210 & 198 & 190 & 182 & 175 & 175 & 167 & 152 & 150 & 150 \\
Extranjeros $^{\mathrm{c}}$ & 172 & 157 & 141 & 123 & 110 & 105 & 95 & 87 & 88 & 92 \\
Total & 38 & 41 & 49 & 59 & 65 & 70 & 72 & 65 & 62 & 58 \\
\hline
\end{tabular}

Fuente: Banco Central del Brasil, Informes sobre la evolución del Sistema Financiero Nacional.

a Incluye bancos múltiples, bancos comerciales y caja económica.

b Incluye bancos nacionales y bancos nacionales con participación extranjera.

c Incluye bancos con capital mayoritariamente extranjero y sucursales de bancos extranjeros.

porcentuales. El mismo cuadro muestra que la privatización no fue la única causa de la consolidación bancaria en Brasil. En 1995-2004 se redujo fuertemente el número de bancos privados, especialmente en la primera etapa del período analizado. El proceso incluyó adquisiciones de importantes instituciones financieras, como el Banco Nacional, el Banco Económico y el Banco Bamerindus, lo que contribuye a explicar la concentración de activos en la segunda etapa. Por lo demás, es interesante comprobar la intensidad del proceso, que fue mucho mayor en la etapa inicial, especialmente en el caso de los bancos públicos. Después, aunque la reducción del número de bancos continuó, perdió velocidad el proceso. En el período 1995-2004, de los 18 casos de reducción del número de bancos públicos 13 tuvieron lugar antes de 1999 y cinco después. En otras palabras, el 72\% de la disminución del número de bancos públicos verificada en el período se produjo en la primera etapa. Algo similar sucedió con los bancos privados, solo que en menor medida. De todos modos, al analizar el tema de la concentración bancaria, se observa la gran participación de los mayores bancos en los activos totales del sector bancario (Banco Central del Brasil, 2006).

Por lo tanto, ha habido un aumento de la participación de los bancos más importantes en los activos totales de la banca. En 1995-1999 solo los 20 mayores bancos aumentaron su participación en los activos totales, y en la etapa siguiente los 20 mayores bancos aumentaron su participación todos los años, salvo en el 2001. En la categoría de los cinco y de los diez mayores bancos, el aumento más significativo de su participación en los activos totales solo se dio después del 2001, año en que se registró la participación más baja de los cinco mayores bancos en todo el período analizado.

Nótese que en la etapa de reducción más rápida del número de bancos, especialmente de los públicos, no aumentó la participación de los más grandes en los activos totales del sector bancario. Sin embargo, en la segunda etapa, que coincidió con la recuperación del peso de los bancos privados nacionales en el sector y en el cual la reducción del número de bancos existentes se hizo más débil, se acrecentó la participación de los bancos principales en los activos totales del sector bancario.

En suma, en el proceso es posible distinguir dos etapas. En la primera (1995-1999), se observa un mayor descenso del número de bancos que funcionan en el sistema, principalmente de los públicos. En la segunda (1999-2004), continúa la reducción del número de bancos, pero aumenta notablemente la participación de los más grandes en los activos totales del sector bancario.

La concentración bancaria y la necesidad de separar el período de análisis en dos etapas se ponen de manifiesto al examinar los índices de concentración del sector bancario (cuadro 2). En este cuadro están representados los índices de Herfindahl-Hirschman (HH), de Hall-Tideman (нт) y de entropía de Theil (т). ${ }^{6}$ En los tres casos hay indicios de aumento de la concentración en el período completo. Sin embargo, en la primera etapa los tres índices apuntan a un aumento de la concentración. En la segunda, en cambio, el índice de Herfindahl-Hirschman y el de entropía de Theil exhibieron oscilaciones, pero al

\footnotetext{
${ }^{6}$ Para los índices de Herfindahl-Hirschman y de Hall-Tideman, el valor tiende a la unidad, en el caso de una estructura de mercado monopolística. Ahora, para el índice de entropía de Theil, la estructura monopolística está indicada por el valor cero, siendo el índice más cercano a la unidad cuanto más la estructura se aproxima al caso de competencia perfecta. Los índices más utilizados son los de Theil y de Herfindahl-Hirschman porque consideran el tamaño relativo de cada empresa y pueden ser estandarizados para facilitar las conclusiones. No obstante, el cálculo de esos índices puede no ser posible si no se conoce el tamaño de todas las empresas que forman parte del sector, por lo cual se recurre a otros índices parciales, como la razón de concentración sectorial (Salazar y David, 2005).
} 
CUADRO 2

Brasil: evolución de los índices de concentración de los activos de los bancos ${ }^{a}$ entre diciembre de 1995 y junio del 2004

\begin{tabular}{|c|c|c|c|c|c|c|c|c|c|c|}
\hline Indices $^{b}$ & $1995 / 12$ & $1996 / 12$ & $1997 / 12$ & $1998 / 12$ & $1999 / 12$ & $2000 / 12$ & $2001 / 12$ & $2002 / 12$ & $2003 / 12$ & $2004 / 06$ \\
\hline $\mathrm{HH}$ & 0,0779 & 0,0789 & 0,0857 & 0,0965 & 0,0924 & 0,0893 & 0,0851 & 0,0906 & 0,0906 & 0,0836 \\
\hline HT & 0,0408 & 0,0412 & 0,0511 & 0,0555 & 0,0566 & 0,0587 & 0,0585 & 0,0645 & 0,0631 & 0,0617 \\
\hline $\mathrm{T}$ & 0,6908 & 0,6923 & 0,6708 & 0,6501 & 0,6420 & 0,6555 & 0,6652 & 0,6540 & 0,6734 & 0,6877 \\
\hline
\end{tabular}

Fuente: elaboración propia sobre la base de Araújo, Neto y Salazar (2005).

a Se refiere a activos totales.

b $\mathrm{HH}=$ índice de Herfindahl-Hirschman. HT= índice de Hall-Tideman. $\mathrm{T}=$ índice de Theil.

final indicaron una concentración menor que la observada en 1999. El índice de Hall-Tideman también presentó oscilaciones, pero mostró en el 2004 una concentración mayor que en 1999.

Cabe preguntarse si la concentración bancaria se ajusta a algún patrón regional. El proceso de consolidación del sector parece tener una relación muy fuerte con la teoría de las economías centrales y periféricas. En el trabajo de Alexandre, Tadeo Lima y Canuto (2005), se concluye que se ha intensificado la concentración de la actividad bancaria en la ciudad de São Paulo, y que esa concentración aparece aún mayor cuando se consideran las operaciones bancarias y no el número de sucursales. En este sentido, lo que podría explicar la fuerte concentración bancaria en São Paulo es el PIB local. Corrêa (2006) corrobora esta conclusión, al mostrar que el movimiento financiero se da principalmente en el entorno de ciudades con intensa concentración demográfica y fuerte dinamismo económico.

En cuanto al número de casas matrices bancarias (en adelante sedes bancarias), también es fácil percibir la concentración existente en São Paulo: en todos los años analizados al menos el $50 \%$ de ellas se ubicaba allí. También el estado de Río de Janeiro alberga un gran número de sedes bancarias, lo que contribuye a la marcada concentración de ellas en el Sudeste, región que pasó de tener el $77 \%$ de las sedes bancarias del país en 1995 a tener casi el 78,7\% de ellas en el 2004. Sin embargo, el porcentaje para el estado de Río de Janeiro bajó considerablemente, de $19 \%$ a $14 \%$. Por lo demás, llama la atención que todas las sedes bancarias de la región Norte estén en el estado de Pará, que todas las de la región Centro-oeste estén en el Distrito Federal, y que además todas sean de bancos públicos. ${ }^{7}$

\footnotetext{
${ }^{7}$ En el 2004, las sedes bancarias ubicadas en el Distrito Federal correspondían al Banco do Brasil, la Caja Económica Federal, el
}

A nivel nacional, la reducción del número de sedes bancarias en el período analizado fue del orden del $25 \%$, siendo más acentuada después de 1998. En 1995, eran 21 las unidades federales que tenían al menos una central bancaria, número que llegó a 22 en 1996. De 1997 en adelante hubo un proceso de concentración regional de sedes, de modo que en el año 2004 eran solo 14 las unidades federales que contaban con al menos una sede bancaria (Banco Central del Brasil, 2006).

Sin embargo, la distribución espacial de la actividad económica, al menos en el caso de Brasil, no parece ser el único factor que explica el grado y la evolución de la concentración bancaria. Cabe destacar que la relación entre la participación en el PIB y la participación en las operaciones de crédito no es directa (Alexandre, Tadeo Lima y Canuto, 2005).

Sicsú y Crocco (2003) averiguan qué lleva a localizar una sucursal en una determinada región. Los factores que motivan la ubicación de una sede bancaria no son necesariamente los mismos que determinan la localización de las sucursales. Los factores de aglomeración, por ejemplo, influirían más en la ubicación de la central bancaria que en la localización de las sucursales. Los autores citados creen que las fuerzas que impulsan la desaglomeración todavía no son lo suficientemente vigorosas como para originar una reubicación de las actividades de los grandes centros financieros, y que con mayor razón cabría pensar que tampoco tienen efecto en la localización de las sucursales. Así, para las sedes tendrían más importancia ciertas características del mercado de trabajo, como la de que pueda satisfacer la demanda de fuerza laboral especializada. El mismo razonamiento vale para la demanda de servicios intermedios y de divulgación de tecnologías e información. En el

Banco de Brasilia (BRB) y el Bancoob. Las ubicadas en el estado de Pará correspondían al BASA y el Banpará. 
caso de la difusión de tecnología, no sería necesaria la aglomeración de las sucursales, pues las sedes podrían traspasarles las innovaciones.

Para la localización de las sucursales se relacionan tres variables que es preciso tener en cuenta: i) el factor demográfico, ii) el factor ingreso y iii) el factor distribución del ingreso. Cabe suponer que estos tres factores tienen una relación positiva con el número de sucursales existentes en una determinada localidad, es decir, que cuanto mayores sean la población y el ingreso y mejor la distribución del ingreso, mayor será el número previsible de sucursales.

Sin embargo, aunque exista concentración bancaria, es importante verificar si el mercado es imperfecto. ${ }^{8}$ Según Belaisch (2003), existe en Brasil una estructura bancaria oligopolística, en la que los ingresos de los bancos se benefician de la diversificación geográfica. ${ }^{9}$ Para Nakane (2001), el sector bancario brasileño no actúa como cartel, pero tampoco se comporta de manera competitiva. Encuentra también que los bancos brasileños utilizan su poder de mercado en el largo plazo más que en el corto. Por lo tanto, el comportamiento del sector bancario de Brasil encajaría en un modelo intermedio entre la competencia perfecta y el monopolio/cartel (Nakane, Alencar y Kanczuk, 2006). Hay indicios de que el aspecto regional influye fuertemente en el grado de competitividad del mercado, así como en la actividad crediticia bancaria.

En lo que atañe al otorgamiento de crédito, también surgen dos aspectos que influyen en los montos que se prestan: i) el concepto de regiones centrales y periféricas, caracterizadas estas últimas por ser más inestables: en ellas los bancos prefieren la liquidez y el crédito está racionado; ii) la concentración de las sedes bancarias, que sumada a la existencia de costos de información, acentúa el desconocimiento de las regiones más distantes del centro decisorio de los bancos, da lugar a una mayor cautela en la concesión

\footnotetext{
${ }^{8}$ Para Tonooka y Koyama (2003, p. 16), con excepción del mercado de letras de cambio, todos los mercados presentan grados de concentración relativamente bajos, tal vez lo suficientemente bajos como para no denotar la existencia de poder de mercado por parte de los bancos. Este resultado fue obtenido en un análisis uno a uno de los productos ofrecidos por entidades bancarias, pero sin considerar la dimensión regional, respecto a la cual los propios autores plantean la posibilidad de que exista un poder de mercado regional.

${ }^{9}$ Los resultados no bastan para señalar que los bancos extranjeros también se comportan de manera oligopolística. En estos casos, los ingresos son más sensibles a los costos. Además, el aumento de la competencia bancaria no puede ser considerado como la fuerza que impulsa la reducción de las tasas de interés en el caso de Brasil (Belaisch, 2003).
}

de crédito a estas regiones. La decisión de prestar dependerá de la confianza que los bancos tengan en la base de información disponible.

$\mathrm{El}$ ambiente de mayor incertidumbre en las regiones periféricas, sumado a la concentración de las sedes bancarias en regiones consideradas centrales, donde la información sobre la periferia es más remota, tiende a llevar a una concentración del crédito que perpetúa e incluso refuerza la situación de desigualdad existente en la economía. Además, los bancos con actividades en el ámbito nacional tienden a otorgar crédito en las regiones periféricas a través de filiales de empresas que también tienen su sede en la región central y con las cuales el banco se ha relacionado en ocasiones anteriores. Amado (2006) argumenta que el proceso de concentración bancaria fue alentado justamente por el hecho de no haberse dado importancia alguna a la existencia de bancos regionales.

Además, si ya se tiende a restringir el crédito en las regiones periféricas, es posible que esa restricción sea más severa para empresas de menor envergadura, por lo difícil que resulta obtener información sobre ellas. En consecuencia, si tales empresas optan por buscar financiamiento bancario, es probable que recurran a los bancos locales, si ellos existen. Estos bancos, por su parte, aprovecharán la relación de proximidad, sabiendo que al cliente le será muy difícil conseguir financiamiento en alguna institución ubicada más lejos.

Según datos del Instituto Brasileño de Geografía y Estadística (IBGE), la participación de São Paulo y el Distrito Federal en el acervo de crédito es superior a su participación en el PIB. El caso paulista refleja la concentración del crédito en el país, lo que tiene como contrapunto la filtración de depósitos en estados como Acre, cuya curva de participación en los depósitos queda por encima de la curva de participación en los créditos. El caso del Distrito Federal parece reflejar el hecho de que en este se encuentran las sedes de los grandes bancos públicos. ${ }^{10}$

Una trayectoria interesante es la del estado de Minas Gerais, que al comienzo de la serie estudiada encajaba en la caracterización de una región con filtraciones del ahorro. Sin embargo, entre el 2002 y el 2004 se redujo la diferencia entre su participación en

\footnotetext{
${ }^{10}$ El Distrito Federal concentra las operaciones de los dos mayores bancos públicos (el Banco do Brasil y la Caja Económica Federal) en forma más intensa que los demás estados (Vasconcelos, Fucidji y otros, 2004, p. 10). Por esa razón, y porque las lógicas de préstamo de los bancos públicos y privados son diferentes, dichos autores decidieron retirar el Distrito Federal del análisis.
} 
los depósitos y su participación en el crédito, con lo cual esas filtraciones prácticamente dejaron de existir en el último año del análisis.

Vale la pena reiterar que la relación entre el crédito y el PIB no es directa. São Paulo presenta una merma en su participación del PIB nacional, pero un aumento de su participación en el acervo de crédito, lo que también en este caso es indicativo de los efectos del proceso de concentración bancaria. Obviamente, São Paulo se beneficia de albergar varios grupos empresariales nacionales y, como se ha dicho, los grandes bancos nacionales prefieren conceder financiamiento a las regiones periféricas a través de empresas cuya casa matriz esté en la región central.

\section{IV \\ Concentración bancaria y concesión de crédito: resultados empíricos en el caso de Brasil}

Sobre la base de los argumentos teóricos presentados hasta ahora, el modelo estimado tiene como variable dependiente el acervo de crédito y puede ser descrito de la manera siguiente:

$$
C_{R E D P C}=\beta_{0}+\beta_{1} D V P C_{i t}+\beta_{2} P_{I B P C}+\beta_{3} P O P A G_{i t}+\beta_{4} \text { THEIL }_{i t}+\beta_{5} \text { SELIC }_{t}+\beta_{6} N U M S E D E_{i t}+\delta_{1} D U M M Y A N O_{i t}+U_{i}
$$

CREDPC $_{i t}: \log$ del acervo per cápita de crédito en la unidad federal $U F_{i}$;

$D_{V P C}:$ log del acervo per cápita de depósitos en la $U F_{i}$;

$P_{P I B C}: \log$ del PIB per cápita de la $U F_{i}$;

$P_{P P A G}:$ : log de la razón población/número de sucursales en la $U F_{i}$;

THEIL $_{i t}$ : índice de Theil en la $U F_{i}$;

SELIC $_{i t-1}: \log$ de la tasa de interés desfasada en un período;

${ }_{N U M S E D E}$ it número de sedes bancarias existentes en la $U F_{i}$;

DUMMYANO ${ }_{1}$ : simulación para el período 1995-1999.

$U_{i}$ : componentes de error (errores idiosincráticos y específicos)

Sicsú y Crocco (2003) tratan de determinar cuáles son las variables clave para definir la localización de una sucursal bancaria. Se espera que donde exista mayor número de sucursales mayor será el crédito concedido. Para poder comparar entre estados, fue preciso elaborar una razón población del estado/número de sucursales (POPAG), buscando reflejar el alcance de la actividad de cada sucursal. ${ }^{11}$ Cuanto mayor sea esa razón, menor será

\footnotetext{
11 Sicsú y Crocco (2003) elaboraron dos índices referentes a la distribución geográfica de las sucursales bancarias con el propósito de facilitar la comparación de los resultados y de comprender mejor cómo se decide su localización. Uno de los índices es la razón entre la proporción de la población estadual en relación con la población nacional y la proporción del número de sucursales del estado sobre el número de sucursales bancarias del país. El segundo índice sigue la misma idea, pero utilizando la proporción del PIB en lugar de la proporción de la población. En el presente trabajo se utiliza una razón
}

la presencia bancaria respecto de la población y, por ende, menor será el crédito concedido en la región.

El ingreso per cápita de la región (PIBPC), así como el grado de concentración del ingreso (THEIL), completan las variables identificadas como relevantes para determinar la localización de la entidad bancaria. A pesar de que estas variables no se han introducido con el mismo formato que en el trabajo de Sicsú y Crocco (2003), las tres están presentes en el modelo: PIB per cápita, índice de Theil y razón población/número de sucursales. Se espera que el PIB per cápita presente signo positivo, o sea, que cuanto mayor sea el ingreso medio de la población de la región, mayor será el acervo de crédito per

más sencilla, simplemente entre la población de la unidad federal y el número de sucursales localizadas en ella. 
cápita. En cuanto al índice de concentración, el signo esperado es ambiguo, pues la concentración del ingreso puede significar tanto un desestímulo - regiones con mayor concentración tienden a tener un menor número de sucursales- como un estímulo, dependiendo de las políticas locales o sectoriales que incentiven el crédito como instrumento del proceso de desconcentración regional del ingreso.

Corresponde subrayar que el número de sucursales utilizado aquí se refiere al número de sucursales con balances registrados en el Banco Central del Brasil. Esto se hizo para conciliar el número de sucursales con los datos relativos al acervo de crédito y de depósitos a la vista que son retirados de los balances en cuestión. En adelante no se hará más esta distinción, denominándose simplemente número de sucursales al número de sucursales registradas.

Tanto los datos de crédito como los de depósito se refieren al acervo existente a diciembre de cada año y resultan de la agregación de un conjunto de variables, según el Plan Contable del Sistema Financiero Nacional (COSIF). ${ }^{12}$ El crédito es denominado operaciones de crédito y está compuesto por préstamos y títulos descontados, financiamientos, financiamientos rurales a la agricultura y la actividad pecuaria, ${ }^{13}$ financiamientos agroindustriales, apropiación de rentas de operaciones de financiamiento rurales y agroindustriales, financiamiento inmobiliario, operaciones especiales, créditos en liquidación y otras operaciones de crédito. Los depósitos están constituidos por los de los gobiernos y del sector privado.

La utilización de la variable depósito en el mismo período, sin rezago, se debe a que los bancos operan activamente en la administración del pasivo, lo que es característico de la evolución del sistema bancario (De Paula y Alves Jr., 2003). ${ }^{14}$ Para los depósitos, se prevé

\footnotetext{
${ }^{12}$ El cosif fue creado por la Circular 1.273 del 29 de diciembre de 1987, con el propósito de unificar los diversos planes contables existentes en la época y uniformar los procedimientos de registro y elaboración de declaraciones financieras (Banco Central del Brasil, 2006).

${ }^{13}$ El financiamiento rural a la agricultura y la actividad pecuaria comprende cuentas de costo/inversión y de comercialización.

${ }^{14}$ La evolución del sistema bancario puede ser descrita de la manera siguiente: en la primera fase, los depósitos son el elemento limitante del sistema, el parámetro para las reservas y créditos. En la segunda fase, los depósitos pasan a ser tratados como medios de pago y los bancos pasan a otorgar crédito como múltiplo de sus reservas. En la tercera fase surge la posibilidad de préstamos entre bancos, liberando así a los préstamos de la restricción de las reservas; estas últimas limitan el sistema en su conjunto y no un banco específico. En la cuarta fase, la autoridad monetaria asume el papel de prestamista de última instancia y todo el sistema queda libre de la restricción impuesta por las reservas. La quinta fase, por último, se caracteriza por la administración de los
}

una relación positiva con el crédito, como lo reconoce ampliamente la teoría.

$\mathrm{Al}$ incluir en el modelo la razón población/número de sucursales, se toma en cuenta la concentración regional de ellas. Pero falta considerar la concentración de las sedes bancarias. Para hacerlo se elaboró la variable NUMSEDE, que se refiere al número de sedes existentes por año en una determinada unidad federal. Los datos fueron extraídos de la información catastral y contable del Banco Central del Brasil. Se prevé que cuanto mayor sea el número de sedes existentes en una región, más fácil será obtener información sobre los clientes y proyectos y más probable que el mercado regional sea competitivo, lo que facilita el acceso al crédito.

En verdad, la variable NUMSEDE es representativa del número de sedes en los datos que hemos analizado. La información obtenida sobre crédito, depósito y número de sucursales se relaciona con bancos comerciales, bancos múltiples con cartera comercial y cajas económicas. Pero la variable NUMSEDE incluye toda la lista de bancos considerados en el trabajo de De Paula y Alves Jr. (2003), en el cual podría figurar alguno que no corresponda a la descripción de los bancos cuyos datos analizamos. No intentamos ajustar la lista por temor a incurrir en algún error al decidir la exclusión (o mantención) de bancos incluidos en ella.

Finalmente, se incluyó una variable ficticia (DUMMYANO) para la etapa 1995-1999 y la variable referente a la tasa de interés (SELIC). ${ }^{15}$ La variable ficticia procura captar la diferencia existente en el proceso de consolidación del sector entre dicha etapa y la de 2000-2004, conforme se analizó en Vasconcelos, Fucidji y otros (2004). De esta manera, para los años 1995-1999, el valor de la variable ficticia es uno y para los años 2000-2004 es cero. Como se indicó, el proceso de consolidación correspondiente a esta primera etapa, en la cual fue mayor el número de bancos que dejaron de existir, tuvo un impacto menor en la concentración de los activos totales del sector bancario que el proceso registrado en la etapa siguiente. En efecto, cabe suponer que, después de la concentración que tuvo lugar en 1995-1999, los bancos pasaron a hacer uso más efectivo del poder de mercado obtenido con el proceso. De este modo, el promedio del acervo de crédito en la etapa inicial debe ser mayor que en los años 2000-2004, concluyendo con un signo positivo para DUMMYANO.

pasivos de los bancos; los bancos otorgan crédito y después buscan nuevos depósitos que equilibren sus balances (Amado, 1998).

${ }^{15}$ Las iniciales SELIC corresponden a Sistema Especial de Liquidación y Custodia. 
La tasa de interés real (SELIC) se calcula sobre la base de la tasa over-SELIC menos el índice de precios al consumo en sentido amplio (IPCA), ${ }^{16}$ por ser un índice con menor influencia de las variaciones cambiarias y por ser el índice de inflación oficial. La serie para la tasa de interés fue la anual, captada diariamente, utilizándose el valor del último día del año. Además, como lo reconoce ampliamente la teoría económica, el efecto de la tasa de interés en la economía tiene un rezago temporal. No obstante, como la serie que analizamos aquí está compuesta por 10 observaciones, la serie temporal resulta insuficiente para la aplicación de pruebas de series temporales que apunten a captar el mejor rezago que pueda usarse. Ante la imposibilidad de adoptar un rezago inferior a un año y entendiendo que uno superior a ese lapso es innecesario para captar los efectos de la tasa de interés en la economía, se optó por el rezago de un período, es decir, de un año. Siguiendo nuevamente la teoría económica, se prevé una relación negativa entre la tasa de interés y la concesión de crédito.

Con la intención de captar los efectos reales de las variables, los datos de crédito (CREDPC) y de depósito ( $D V P C)$ fueron ajustados a valores de diciembre del 2004, utilizando el IPCA. Para la variable PIB per cápita (PIBPC) se adoptó el deflactor implícito, históricamente utilizado en la corrección de los valores corrientes del PIB. Para las demás variables no fue necesario adoptar tipo alguno de corrección por inflación.

En cuanto al índice de concentración del ingreso de Theil (THEIL), la serie de datos registra una omisión en el año 2000 (año de realización del censo). Como forma de estimar los valores para ese año, a fin de tener datos en panel equilibrados, ${ }^{17}$ se realizó una interpolación teniendo en cuenta los años 1997 al 2003, dando una mayor ponderación a los años más próximos al 2000. Con el uso de varios años para realizar la interpolación y con dicha ponderación se procuró suavizar la serie y captar mejor la tendencia.

Finalmente, para posibilitar el análisis de sensibilidad, las variables fueron convertidas a logaritmos, con excepción del índice de Theil, el número de sedes y la variable ficticia para la etapa 1995-1999. Además, se utilizaron las variables crédito per cápita, depósito per

\footnotetext{
${ }^{16}$ Se utilizó el índice de precios al consumo en sentido amplio (IPCA) de diciembre a diciembre y no el promedio del año, toda vez que los datos analizados corresponden a acervo.

${ }^{17}$ Existen métodos que permiten la estimación de datos en panel no equilibrados. Véase más detalle en Wooldridge (2002). No obstante, dado que la serie aquí analizada no está compuesta por un gran número de años, se optó por equilibrar los datos en panel en lugar de descartar datos de la serie.
}

cápita y PIB per cápita para permitir una mejor comparación o dimensionamiento del efecto del proceso de concentración bancaria en el otorgamiento de crédito.

Aunque el trabajo de Vasconcelos, Fucidji y otros (2004) dejó fuera el Distrito Federal, como se mencionó antes, para evitar un posible sesgo en los resultados debido a las características inherentes a esa región, en el presente artículo se consideran todas las unidades federales, puesto que no solo el Distrito Federal presenta algunas características específicas, sino que también las presentan el estado de São Paulo y otros. Son justamente esas características las que son captadas por los modelos de datos en panel. Asimismo, contrariamente a lo expuesto en el trabajo citado, aquí no se trata de analizar las diferencias existentes entre los préstamos de los bancos públicos y privados, sino el efecto de la concentración bancaria en la concesión de crédito.

Pese a que el tema legal y de regulación es pertinente para el análisis, no lo abordaremos en este estudio porque todos los estados de Brasil tienen el mismo marco jurídico en lo que se refiere al sistema bancario.

Los datos de crédito, depósitos y sucursales provienen del Banco Central del Brasil. Los datos de PIB per cápita, la serie de los índices de concentración de Theil y la serie de tasa de interés, así como las tasas de inflación y los datos sobre población, fueron obtenidos del Instituto de Investigación Económica Aplicada (IPEA) y del IBGE. A continuación se presentan los datos estadísticos descriptivos (cuadro 3).

Con las variables antes descritas y con el propósito de demostrar que el proceso de concentración bancaria llevó a una concentración del crédito, se realizó un análisis de datos en panel, con información sobre las 27 unidades federales en 1995-2004.

Dado que los datos en panel contienen observaciones periódicas de las mismas variables, ofrecen muchas posibilidades de resolver cuestiones que los modelos de corte transversal no permiten tratar adecuadamente. Cameron y Trivedi (2005) opinan que el modelado con datos en panel hace más precisa la estimación. El análisis de datos en panel ofrece las ventajas siguientes: i) considera la heterogeneidad individual (en este caso, de las unidades federales); ii) ofrece más información, mayor variabilidad, menor colinealidad entre las variables, mayor grado de libertad y mayor eficiencia; iii) es mejor para estudiar la dinámica de ajuste; iv) es mejor para identificar y cuantificar efectos que simplemente no se pueden detectar en un corte transversal puro o en una serie temporal pura, y v) permite la construcción y prueba de modelos de comportamiento más complejos (Baltagi, 2005). 
Brasil: datos estadísticos descriptivos, 1995-2004

\begin{tabular}{lccccc}
\hline \multicolumn{1}{c}{ Variable } & Observaciones & Promedio & Desviación estándar & Mínimo & Máximo \\
\hline CREDPC & 270 & 74,163 & 0,9643 & 58,830 & 104,674 \\
DVPC & 270 & 58,667 & 0,5971 & 48,132 & 80,727 \\
PIBPC & 270 & 87,607 & 0,5321 & 76,695 & 99,756 \\
POPAG & 270 & 95,831 & 0,4840 & 87,115 & 105,355 \\
THEIL & 270 & 0,6850 & 0,1116 & 0,3388 & 0,9608 \\
SELIC & 270 & 25,784 & 0,5012 & 18,617 & 35,218 \\
NUMSEDE & 270 & 46,407 & 130,902 & 0 & 76 \\
DUMMYANO & 270 & 0,5 & 0,5009 & 0 & 1 \\
\hline
\end{tabular}

Fuente: elaboración propia.

Existen diferentes modelos que pueden ser estimados con datos en panel: i) los agrupados (pooled), ii) los de efecto aleatorio y iii) los de efecto fijo. Además, hay diferentes formas de estimar los coeficientes, siendo las más habituales: i) los mínimos cuadrados ordinarios agrupados; ii) efecto between; iii) considerando el efecto fijo; iv) tomando la primera diferencia, y v) considerando el efecto aleatorio. El cuadro 4 muestra la congruencia de los estimadores, en modelos lineales, dada la manera de obtener los coeficientes y el modelo en panel estimado.

Es posible que el modelo que proponemos aquí presente variables endógenas, específicamente de depósitos (DVPC) y PIB (PIBPC). No obstante, las variables están altamente correlacionadas con su propio rezago, lo que afecta la utilización de ellas como instrumentos. Por esto y por la dificultad de disponer de otros instrumentos eficaces, se estimará el modelo partiendo de la hipótesis de exogeneidad. Cabe señalar que lo más recomendable para las variables del PIB (PIBPC) y de la tasa de interés (SELIC) sería utilizar las respectivas expectativas, pero no se dispone de una serie de datos para todo el período que se analiza.

Se observa a través de la matriz de correlación (cuadro 5) que la relación positiva entre el índice de concentración del ingreso (THEIL) y la razón población/ número de sucursales (POPAG) corrobora el argumento de Sicsú y Crocco (2003): cuanto más concentrado está el ingreso en una determinada región, menor es el número de sucursales necesarias para captar el ingreso disponible y mayor será la razón población/sucursales. De la misma manera, cuanto mayor sea la razón población/ número de sucursales, menor será el crédito per cápita, lo que indica que la presencia de sucursales bancarias es fundamental para la concesión de crédito.

El PIBPC presenta una relación positiva y relevante tanto con el acervo de crédito (CREDPC), como con el acervo de depósitos (DVPC), conforme lo prevé la teoría. La tasa de interés (SELIC) tiene una relación negativa con el PIв per cápita, lo que también prevé la teoría, posiblemente por los efectos negativos que ejerce el aumento de los intereses en el crédito; sin embargo, muestra una relación positiva con los acervos de crédito y depósitos. Esta relación puede deberse a que los depósitos que aquí se analizan corresponden al acervo de depósitos, que puede sufrir algún tipo de corrección.

El número de sedes (NUMSEDE) tiene una relación positiva con el acervo de crédito, lo que refuerza la idea de que la presencia en el ámbito regional no solo de sucursales sino también de sedes influye en la concesión de crédito. Además, se puede comprobar que existe una relación negativa entre el número de sedes (NUMSEDE) y la razón población/número de sucursales (POPAG); esto quiere decir que cuanto mayor sea el número de sedes bancarias en una determinada región, mayor será la presencia de sucursales ubicadas en ella, lo que reduce la razón población/número de sucursales.

Otra correlación que corrobora la hipótesis puesta a prueba en este estudio es la obtenida por la variable ficticia para 1995-1999 (DUMMYANO). Esa correlación muestra una relación positiva con el acervo de crédito per cápita, lo que indica que el acervo de crédito en esa etapa era, en promedio, superior al obtenido en la siguiente.

Por último, en lo que se refiere a las relaciones consideradas en la matriz de correlación, y suponiendo que existe una fuerte correlación entre variables para valores absolutos superiores a 0,8 , vemos que el acervo de depósitos está fuertemente correlacionado con el PIB per cápita y que la tasa de interés está fuertemente correlacionada con la variable ficticia en 1995-1999.

Para verificar si efectivamente existe multicolinealidad en el modelo, se calculó el factor inflación de la varianza (FIV). Es práctica en las publicaciones 
Brasil: modelos lineales de datos en panel

\begin{tabular}{lcc}
\hline \multicolumn{1}{c}{ Método de estimación } & \multicolumn{2}{c}{ Modelo supuesto } \\
\cline { 2 - 3 } & De datos agrupados & De efectos aleatorios \\
\hline $\begin{array}{ll}\text { De mínimos cuadrados ordinarios agrupados } \\
\text { Efecto Between }\end{array}$ & Congruente & Congruente \\
De efecto fijo & Congruente & Congruente \\
En primera diferencia & Congruente & Congruente \\
De efecto aleatorio & Congruente & Congruente \\
\end{tabular}

Fuente: Cameron y Trivedi (2005, p. 699).

CUADRO 5

Brasil: matriz de correlación, 1995-2004

\begin{tabular}{|c|c|c|c|c|c|c|c|c|}
\hline & CREDPC & $D V P C$ & PIBPC & POPAG & THEIL & SELIC & NUMSEDE & DUMMYANO \\
\hline CREDPC & 1,0000 & & & & & & & \\
\hline$D V P C$ & 0,7361 & 1,0000 & & & & & & \\
\hline PIBPC & 0,6895 & 0,8087 & 1,0000 & & & & & \\
\hline POPAG & $-0,7859$ & $-0,6579$ & $-0,7581$ & 1,0000 & & & & \\
\hline THEIL & $-0,0715$ & $-0,3186$ & $-0,4666$ & 0,2952 & 1,0000 & & & \\
\hline SELIC & 0,2371 & 0,0232 & $-0,0667$ & $-0,0252$ & 0,1091 & 1,0000 & & \\
\hline DUMMYANO & 0,3217 & $-0,0576$ & $-0,0729$ & $-0,0904$ & 0,1544 & 0,8127 & 0,0284 & 1,0000 \\
\hline
\end{tabular}

Fuente: elaboración propia.

especializadas considerar que existe multicolinealidad severa cuando el FIV excede el valor 5 . En este caso el FIV es inferior a 5 para todas las variables del modelo. Por lo tanto, el modelo fue estimado sin excluir variable alguna de las aquí analizadas.

Todos los modelos fueron estimados ajustando la matriz de varianzas a la forma robusta. Como muestra el cuadro 6, el resultado obtenido con datos agrupados fue el más cercano a los resultados que se esperaban. Tomando los resultados del modelo con datos agrupados, todas las variables son estadísticamente significativas al $1 \%$, salvo el PIB per cápita y la tasa de interés, que son significativas al $10 \%$.

Al analizar el modelo de datos agrupados se comprueba que, como se esperaba, cuanto mayor es el acervo de depósitos per cápita y mayor el PIB per cápita, mayor será el acervo de crédito per cápita. Lo signos obtenidos para la razón población/número de sucursales y para el número de sedes corroboran la hipótesis aquí postulada. De esta manera, cuanto mayor es la razón población/sucursales, menor es el acervo de crédito per cápita, lo que revela una de las consecuencias negativas del proceso de concentración bancaria: la concentración regional de las sucursales bancarias.
Además, cuanto mayor sea el número de sedes bancarias en una determinada región, mayor será el acervo de crédito per cápita. No obstante, el valor del coeficiente NUMSEDE es bajo, lo que revela un impacto reducido en dicho acervo. Con estos dos resultados se refuerza el análisis anterior de los efectos adversos del proceso de consolidación bancaria sobre la concesión de crédito en el ámbito regional. Se observa, sin embargo, que el proceso de reubicación de las sucursales tuvo un efecto mayor en el crédito que la concentración de las sedes.

Estos resultados permiten suponer que las sucursales tienen algún grado de autonomía para decidir respecto al crédito bancario. $\mathrm{O}$ bien que la naturaleza de los créditos concedidos - de menor cuantía y en su mayoría a personas físicas - hace que la decisión pueda ser adoptada a nivel de sucursales.

Conforme a lo observado en la matriz de correlación, la reducción del número de sedes está negativamente relacionada con la variable $P O P A G$. Además, teniendo en cuenta las motivaciones del proceso de consolidación, no es descaminado suponer que existe una relación de causalidad entre estas variables, siendo la reducción del número de sedes una de las causas del aumento de la razón población/sucursal. 
CUADRO 6

Brasil: resultados del trabajo ${ }^{a}$

\begin{tabular}{|c|c|c|c|}
\hline $\begin{array}{l}\text { Variables } \\
\text { independientes }\end{array}$ & $\begin{array}{l}\text { Mínimos } \\
\text { cuadrados } \\
\text { ordinarios } \\
\text { agrupados }\end{array}$ & $\begin{array}{l}\text { Efecto } \\
\text { aleatorio }\end{array}$ & $\begin{array}{l}\text { Efecto } \\
\text { fijo }\end{array}$ \\
\hline$D V P C$ & $\begin{array}{l}0,666^{\mathrm{b}} \\
(0,093)\end{array}$ & $\begin{array}{r}0,497^{b} \\
(0,121)\end{array}$ & $\begin{array}{r}0,319^{c} \\
(0,144)\end{array}$ \\
\hline PIBPC & $\begin{array}{l}0,177^{\mathrm{d}} \\
(0,107)\end{array}$ & $\begin{array}{c}0,159 \\
(0,178)\end{array}$ & $\begin{array}{l}-0,403 \\
(0,396)\end{array}$ \\
\hline POPAG & $\begin{array}{r}-0,834^{\mathrm{b}} \\
(0,084)\end{array}$ & $\begin{array}{r}-0,959^{\mathrm{b}} \\
(0,144)\end{array}$ & $\begin{array}{r}-1,014^{\mathrm{b}} \\
(0,349)\end{array}$ \\
\hline THEIL & $\begin{array}{r}1,831^{\mathrm{b}} \\
(0,309)\end{array}$ & $\begin{array}{r}1,366^{\mathrm{b}} \\
(0,364)\end{array}$ & $\begin{array}{r}1,006^{\mathrm{b}} \\
(0,375)\end{array}$ \\
\hline$S E L I C$ & $\begin{array}{r}-0,158^{d} \\
(0,092)\end{array}$ & $\begin{array}{c}-0,104 \\
(0,079)\end{array}$ & $\begin{array}{l}-0,065 \\
(0,101)\end{array}$ \\
\hline NUMSEDE & $\begin{array}{c}0,009^{\mathrm{b}} \\
(0,002)\end{array}$ & $\begin{array}{c}0,010^{\mathrm{b}} \\
(0,003)\end{array}$ & $\begin{array}{c}0,019 \\
(0,016)\end{array}$ \\
\hline DUMMYANO & $\begin{array}{r}0,664^{\mathrm{b}} \\
(0,101)\end{array}$ & $\begin{array}{c}0,610^{\mathrm{b}} \\
(0,086)\end{array}$ & $\begin{array}{r}0,523^{\mathrm{b}} \\
(0,114)\end{array}$ \\
\hline Constante & $\begin{array}{r}8,746^{b} \\
-1,605\end{array}$ & $\begin{array}{l}11,300^{b} \\
-2,755\end{array}$ & $\begin{array}{l}17,944^{b} \\
-4,144\end{array}$ \\
\hline Observaciones & 243 & 243 & 243 \\
\hline $\begin{array}{l}\mathrm{R}^{2} \\
\text { Valor de } \mathrm{F}\end{array}$ & 0,84 & 0,54 & $\begin{array}{c}0,56 \\
44,39 \\
0,0000\end{array}$ \\
\hline Factor de inflación de la varianza & 2,79 & & \\
\hline $\begin{array}{l}\text { Estadístico RHO } \\
\text { Prueba de HAUSMAN }\end{array}$ & & $\begin{array}{c}0,3361 \\
12,52 \\
0,0848\end{array}$ & 0,6602 \\
\hline Prueba de $B R E U S C H-P A G A N$ & & $\begin{array}{l}70,66 \\
0,0000\end{array}$ & \\
\hline
\end{tabular}

Fuente: elaboración propia con datos del trabajo.

a Las desviaciones estándares robustas figuran entre paréntesis.

b Estadísticamente significativo al $1 \%$.

c Estadísticamente significativo al 5\%.

d Estadísticamente significativo al $10 \%$.

Una de las maneras de tratar de reducir el impacto negativo de la baja del número de sucursales es la utilización de corresponsales bancarios que, como se vio, pueden inclusive tramitar solicitudes de préstamos y de financiamiento. En la hipótesis de que, por una cuestión de logística, la solicitud se dirige a la sucursal más cercana, este efecto estaría captado en nuestro análisis, pues el enfoque es regional y no municipal. Además, en caso de que el corresponsal bancario presentara un desempeño positivo por encima del promedio de la región, podría invertirse el signo de la variable $P O P A G$ e inclusive tornarla no significativa. Como el resultado fue el que se esperaba, hay indicios de que la figura del corresponsal bancario no altera el impacto negativo que acarrea para la concesión de crédito la reducción del número de sucursales respecto de la población.
Otro aspecto que vale la pena destacar es la confirmación empírica de la necesidad de dividir en dos el período de análisis. La etapa inicial 1995-1999 presenta un acervo de crédito per cápita superior al que se observa en los años 2000-2004. Cabe inferir entonces que tras una primera etapa de profundos ajustes y fuerte concentración del sistema bancario, los bancos que emergieron del proceso pasaron a otorgar crédito de manera más racionalizada.

Obviamente, el entorno económico cambió. Sin embargo, no parece ser ese el origen de la baja del acervo de crédito per cápita en los años 1999-2004, pues justamente en 1995-1999 se registraron las crisis de México, Asia y Rusia y la de Brasil, que puso fin a la flotación cambiaria en 1999 y llevó a la adopción de la política de metas de inflación. En 1999-2004 solo hubo una crisis con repercusión internacional, la energética, de modo que el descenso del acervo de crédito per cápita en esos años no puede atribuirse al entorno externo y la ocurrencia de crisis.

No sería exagerado afirmar entonces que hay indicios de que los bancos intensificaron el racionamiento del crédito en la segunda etapa, cuando ya disfrutaban de un poder de mercado superior al de la etapa anterior.

Contrariamente al resultado obtenido en la matriz de correlación, la tasa de interés con rezago de un año muestra un efecto negativo en el crédito, lo que corrobora lo encontrado por Araújo y Dias (2006). Dada la realidad económica que vivía Brasil en esos años, se puede vislumbrar la magnitud de los efectos de esa tasa en el crédito y, por ende, en el desarrollo regional. En la misma época en que se producía la consolidación del sector bancario, el país soportaba tasas de interés reales elevadas, lo que ampliaba el impacto en la concesión de crédito.

Las variables acervo de depósitos, PIB per cápita y tasas de interés están en forma logarítmica, lo que facilita el análisis de sensibilidad del acervo de crédito a las fluctuaciones de estas variables. Es posible, entonces, inferir que una variación del $1 \%$ en el acervo de depósitos per cápita eleva aproximadamente en un $0,7 \%$ el acervo de crédito per cápita. Una variación de ese orden en el PIB per cápita significa un incremento de un $0,18 \%$ en el acervo de crédito. Y cada punto porcentual de aumento de la tasa de interés significa una reducción en torno al $0,16 \%$ del acervo de crédito per cápita.

Finalmente, conviene subrayar que el modelo con el que aquí se trabaja presenta un $\mathrm{R}^{2}$ igual a $84 \%$, lo que demuestra su elevada capacidad explicativa.

Analizando los resultados para los modelos de efectos aleatorios y efectos fijos, se observa que los 
hallazgos, a pesar de perder significación, siguen en la misma línea que el resultado esperado y obtenido para el modelo con datos agrupados. La pérdida de significación de algunas variables podría estar relacionada justamente con el hecho de que el modelo de efectos fijos pasa a considerar efectos específicos de cada unidad federal. Es admisible que existan características singulares de cada región que afecten el acervo de crédito, es decir, que existan dinámicas regionales diferenciadas.

De todas formas, el modelo de efecto aleatorio ofrece resultados más cercanos a los obtenidos con datos agrupados que a los logrados mediante un modelo de efecto fijo, y este es precisamente el modelo más adecuado, conforme al resultado obtenido con la prueba de Hausman. En lo que se refiere a la autocorrelación serial de los residuos, para el modelo de efecto aleatorio no existe autocorrelación al 5\%.

Además, la prueba de Breusch-Pagan rechaza la hipótesis de que la varianza del componente específico sea igual a cero, e indica que sería preferible utilizar un modelo de efecto aleatorio, en relación con el modelo de datos agrupados. En el mismo sentido, el estadístico RHO revela que la varianza del componente específico en relación con la varianza total del residuo es elevada, en especial en el caso del efecto fijo, lo que demuestra la importancia de dicho componente.

Al estimar el modelo de efecto aleatorio la variable del PIB per cápita (PIBPC) pierde significación, así como la tasa de interés (SELIC). Como tasa de interés, según se explicó en la sección anterior, se utilizó la tasa overselic, pero esta es solo la tasa básica de la economía y no la tasa obtenida en el momento de la concesión del crédito. Como se sabe, en 1995-2004 la economía brasileña convivía con altos márgenes bancarios, lo que daba lugar a elevadas tasas de interés para el tomador final. Por lo tanto, la pérdida de significación de la tasa de interés, tanto con el modelo de efectos aleatorios como con el de efectos fijos, puede deberse a la utilización de la tasa de interés básica de la economía.

Los demás resultados correspondientes al modelo de efectos aleatorios son semejantes a los obtenidos con el modelo de datos agrupados, pero difieren en la magnitud de los coeficientes. En este sentido, destaca la variación obtenida para el coeficiente de la razón población/número de sucursales (POPAG), que torna aún más importante los efectos de esta variable sobre el crédito.
Por último — pero no por ello menos importante-, el proceso de privatización puede explicar en gran medida, pero no por sí solo, la fuerte reducción del número de sedes bancarias. Además de las privatizaciones hubo varias liquidaciones de bancos estaduales, así como fusiones y adquisiciones entre bancos. Los resultados indican que fue más significativo el fenómeno de reubicación de sucursales que el de disminución del número de sedes (el coeficiente de la variable sede bancaria es estadísticamente significativo pero poco relevante). No obstante, la variable POPAG está negativamente correlacionada con la variable $S E D E$, indicando que la reducción del número de sedes podría determinar un aumento de la razón población/número de sucursales. Este hecho parece corroborarse por la práctica común, después de una fusión o adquisición, de tratar de obtener beneficios de sinergia y escala. En particular, después de las privatizaciones bancarias fue habitual el cierre de sucursales, especialmente en plazas menos dinámicas.

En trabajos con análisis de datos en panel suele recurrirse al expediente de presentar el mismo modelo en secciones transversales para todos los años estudiados, con miras a que se comprenda mejor la dinámica del proceso y a corroborar los resultados obtenidos, dando así mayor robustez al modelo. Sin embargo, como nuestro modelo incluye una variable con rezago en el tiempo, no es posible realizar tal prueba de robustez.

Además, si para verificar la robustez del modelo se reemplaza el índice de Theil por el índice de Gini, los resultados prácticamente no cambian, salvo en el caso del coeficiente mismo de la variable concentración, que pasa a ser claramente mayor, y de la variable PIB per cápita, que deja de ser estadísticamente significativa.

En todo caso, teniendo en cuenta la matriz de correlación y los resultados obtenidos con el modelo de datos agrupados y de datos en panel de efectos aleatorios, que fue el método indicado por la prueba de Hausman, lo que se comprueba es que los resultados corroboran la hipótesis formulada y el análisis realizado en las secciones anteriores.

En otras palabras, si se analiza el proceso de consolidación del sector bancario en Brasil desde el ángulo regional, su efecto en la concesión de crédito es adverso. La región periférica ve disminuir la red de sucursales bancarias que la atiende y prácticamente deja de tener sedes bancarias, pasando a vivir en un ámbito en que el crédito está aún más racionado. 


\section{$\mathrm{V}$}

\section{Conclusiones}

En este artículo se buscó captar los efectos de la concentración bancaria en la concesión de crédito, teniendo como hipótesis que la consolidación del sector bancario genera efectos adversos en la concesión de crédito. Se puede decir que esa hipótesis fue corroborada por los resultados obtenidos. Se hizo evidente que la presencia de sucursales y sedes bancarias en las regiones está relacionada positivamente con el crédito. Por lo tanto, la reubicación de sucursales en las regiones más desarrolladas del país, así como la concentración regional de sedes bancarias, reducen el acervo de crédito per cápita en las regiones restantes. Además, los resultados muestran que el proceso de reubicación de sucursales afecta más al crédito que el proceso de concentración de sedes.

El hecho de que las regiones que perdieron sedes bancarias y pasaron a exhibir una mayor razón población/ número de sucursales sean a la vez las menos desarrolladas sugiere la existencia de un mecanismo que dificulta su desarrollo. En cuanto a los efectos de la concentración cambiaria, la observación empírica muestra que después de un período de fuerte ajuste, los bancos empezaron a racionar mucho más el crédito, tal vez en virtud del mayor poder de mercado que pasaron a tener.

Los demás resultados obtenidos indican que el modelo se alinea con la teoría existente, conforme a la cual tanto el PIB per cápita como el acervo de depósitos tienen efectos favorables sobre el crédito, en tanto que la variación de la tasa de interés tiene un efecto inverso en el acervo crediticio.

Una posibilidad de obtener resultados más robustos y que puede dar pie a una investigación posterior es la de adoptar expectativas de crecimiento económico y de tasas de interés e inflación como variables explicativas. Otra posibilidad es detallar los datos por municipio y desagregar el crédito por tipo de operación (por producto ofrecido por la entidad bancaria). Según Corvosier y Gropp (2001), la naturaleza del producto es un elemento importante en el análisis de la concentración bancaria y de sus efectos sobre las tasas cobradas. Por lo demás, los bancos de Brasil tienen en su cartera títulos de la deuda pública que garantizan una liquidez y una rentabilidad bastante significativas. Con una deuda neta del sector público que en el 2006 superó el 47\% del PIB, los bancos - privados y públicos- en definitiva garantizan su rentabilidad con esos títulos. El impacto de esta estrategia en la oferta de crédito no debe menospreciarse y probablemente explica parte de la contracción del crédito en Brasil. De hecho, lo que hacen los bancos con su demanda de títulos de la deuda pública es ofrecer crédito a la Tesorería Nacional.

Como subrayan Cavalcante, Crocco y Jayme Jr. (2004), en la oferta de crédito influye no solo la preferencia por la liquidez, sino también el grado de desarrollo del sistema bancario. Conviene entonces estudiar más a fondo cuál es el grado de desarrollo que ha alcanzado el sistema bancario y financiero de Brasil. Teniendo en cuenta los resultados obtenidos, sería interesante crear un mecanismo que estimule la desconcentración de las sedes bancarias, el que podría tomar la forma de menores tasas de encaje bancario o de reducción de los impuestos cobrados. Asimismo, según destacan Jayme Jr. y Crocco (2007), los fondos regionales de desarrollo tienen gran importancia y pueden encauzar créditos en condiciones más favorables hacia las regiones menos dinámicas. A estos fondos podría aplicarse el mismo principio que utiliza el Banco Nacional de Desarrollo Económico y Social (BNDES) con sus agentes financieros; es decir, el gobierno podría abrir a todas las instituciones financieras el uso de los recursos de estos fondos, con lo cual acrecentaría la competencia e inclusive la transparencia de este financiamiento.

Finalmente, con algunos ajustes al marco legal y de regulación del sistema financiero y jurídico de Brasil - tema que escapa al ámbito del presente trabajo- se podría crear un clima más propicio para el otorgamiento de crédito. De igual manera, el fortalecimiento de los mercados de capital como alternativa para captar recursos puede abrir una nueva posibilidad a las empresas de mayor envergadura. 
Alexandre, M., G. Tadeo Lima y O. Canuto (2005): Distribuição espacial da atividade bancária no Brasil: dimensões e indicadores, Nova economia, vol. 15, № 1, Belo Horizonte, Universidad Federal de Minas Gerais, enero-abril.

Amado, A. (1998): Moeda, financiamento, sistema financeiro e trajetórias de desenvolvimento regional desigual: a perspectiva pós-Keynesiana, Revista de economia política, vol. 18, $\mathrm{N}^{\mathrm{o}} 1$, São Paulo, Centro de Economía Política, enero-marzo.

(2006): Impactos regionais do recente processo de reestruturação bancária no Brasil, en M. Crocco y F.G. Jayme Jr., Moeda e território: uma interpretação da dinâmica regional brasileira, Belo Horizonte, Autêntica.

Araújo, E. y J. Dias (2006): Endogeneidade do setor financeiro e crescimento econômico: uma análise empírica para a economia brasileira (1980-2003), Revista de economia contemporânea, vol. 10, No 3, Rio de Janeiro, Universidad Federal de Rio de Janeiro, septiembre-diciembre.

Araújo, L., P.M.J. Neto y D.A. Salazar (2005): Competição e concentração entre os bancos brasileiros, Anais do Encontro de Economia da Região Sul, Porto Alegre, ANPEC-SUL.

Arestis, P. y P. Demetriades (1997): Financial development and economic growth: assessing the evidence, The Economic Journal, vol. 107, № 442, Oxford, Reino Unido, Blackwell Publishing, mayo.

Baltagi, B. (2005): Econometric Analysis of Panel Data, Nueva York, Wiley \& Sons.

Banco Central de Brasil (2006): Informações cadastrais e contábeis, Sistema Financeiro Nacional, Brasilia. Disponible en: http:// www.bancocentral.gov.br

Baum, C., M. Caglayan y N. Ozkan (2004): The Second Moments Matter: the Response of Banking Lending Behavior to Macroeconomic Uncertainty, Leicester, Universidad de Leicester, mayo.

Beck, T., A. Demirgüç-Kunt y R. Levine (2006): Bank concentration, competition, and crises: first results, Journal of Banking and Finance, vol. 30, $\mathrm{N}^{\circ}$ 5, Amsterdam, Elsevier.

Belaisch, A. (2003): Do Brazilian Banks Compete?, IMF Working Papers, $\mathrm{N}^{\mathrm{o}}$ 03/113, Washington, D.C., Fondo Monetario Internacional.

Blum, D. y M. Nakane (2005): O impacto de requerimentos de capital na oferta de crédito bancário no Brasil, Anais do XXXIII Encontro Nacional de Economia, Natal, Associação Nacional dos Centros de Pósgraduação em Economia (ANPEC).

Cameron, A.C. y P. K. Trivedi (2005): Linear panel models: basics, Microeconometrics: Methods and Applications, Cambridge, Cambridge University Press.

Cavalcante, A., M. Crocco y F.G. Jayme Jr. (2004): Preferência pela liquidez, sistema bancário e disponibilidade de crédito regional, texto para discusión, $N^{\circ}$ 237, Belo Horizonte, Universidad Federal de Minas Gerais.

Corrêa, V. P. (2006): Distribuição de agências bancárias e concentração financeira nas praças de maior dinamismo econômico: um estudo dos anos 1980 e 1990, en M. Crocco y F.G. Jayme Jr., Moeda e território: uma interpretação da dinâmica regional brasileira, Belo Horizonte, Autêntica.

Corvosier, S. y R. Gropp (2001): Bank Concentration and Retail Interest Rates, Frankfurt, Banco Central Europeo, julio.

De Paula, L.F.R y A.J. Alves Jr. (2003): Comportamento dos bancos, percepção de risco e margen de segurança no ciclo minskiano, Análise econômica, vol. 21, № 29, Porto Alegre, Universidade Federal do Rio Grande do Sul.

De Paula, L.F.R. y M.B.L. Marques (2004): Tendências recentes da consolidação bancária no mundo e no Brasil, documento presentado en el Encuentro Nacional de Economía Política (Uberlândia, 8 de junio), Uberlândia, Sociedade Brasileira de Economia Política.

Demetriades, P.O. y K.A. Hussein (1996): Does financial development cause economic growth? Time series evidence from 16 countries,
Journal of Development Economics, vol. 51, № 2, Amsterdam, Elsevier.

Freitas, C.E. (2005): A experiência brasileira com instituições financeiras de desenvolvimento, serie Financiamiento del desarrollo, $\mathrm{N}^{\circ} 155$, LC/L.2328-P, Santiago de Chile, Comisión Económica para América Latina y el Caribe (CEPAL). Publicación de las Naciones Unidas, $\mathrm{N}^{\mathrm{o}}$ de venta: P.05.II.G.115.

IPEA (Instituto de Investigación Económica Aplicada) (2006): Dados macroeconômicos e regionais, Brasilia. Disponible en: http:// www.ipeadata.gov.br

Jayaratne, J. y P.E. Strahan (1996): The finance-growth nexus: evidence form bank branch deregulation, The Quartely Journal of Economics, vol. 111, Cambridge, Massachusetts, The мIт Press, agosto.

Jayme Jr., F.G. y M. Crocco (2007): Fiscal policy, credit availability and financing of regional policies in Brazil, en P. Arestis y A. Saad-Filho, Political Economy of Brazil, Londres, Palgrave Macmillan.

Keynes, J. M. (1992), A teoria geral do emprego, do juro e da moeda, São Paulo, Ed. Atlas.

Levine, R. (1997): Financial development and economic growth: views and agenda, Journal of Economic Literature, vol. 35, $\mathrm{N}^{\circ} 2$, Nashville, Tennessee, American Economic Association.

Matos, O.C. (2002), Desenvolvimento do sistema financeiro $e$ crescimento econômico no Brasil: evidências de causalidade, trabalhos para discussão, $\mathrm{N}^{\circ}$ 49, Brasilia, Banco Central de Brasil, septiembre.

Meirelles, H. de C. (2006): Tendências de financiamento ao setor privado, Brasilia, Banco Central de Brasil. Disponible en: http:// www.bcb.gov.br/?APRES200611>

Minsky, H.P. (1986): Stabilizing an unstable economy, New Haven, Yale University Press.

Nakane, M. (2001): A Test of Competition in Brazilian Banking, textos para discusión, $\mathrm{N}^{\circ}$ 12, Brasilia, Banco Central de Brasil, marzo.

Nakane, M., L. Alencar y F. Kanczuk (2006), Demand for Bank Services and Market power in Brazilian Banking, textos para discusión, $\mathrm{N}^{\circ}$ 107, Brasilia, Banco Central de Brasil, junio.

Neuberger, D. (1997): Structure, Conduct and Performance in Banking Markets, texto para discusión, $\mathrm{N}^{\circ} 12$, Rostock, Universidad de Rostock.

Rajan, R.G. y L. Zingales (1998): Finance dependence and growth, The American Economic Review, vol. 88, No 3, Nashville, Tennessee, American Economic Association, junio.

Salazar, P. y A. David (2005): Medidas de concentração na indústria bancária: algumas observações para Brasil, Equador e Panamá, inédito.

Sicsú, J. y M. Crocco (2003): Em busca de uma teoria da localização das agências bancárias: algumas evidências do caso brasileiro, Economia, vol. 4, № 1, Associação Nacional dos Centros de Pósgraduação em Economia, Niterói, enero-junio.

Stiglitz, J. y A. Weiss (1981): Credit rationing in markets with imperfect information, The American Economic Review, vol. 71, No 3 , Nashville, Tennessee, American Economic Association, junio.

Tonooka, E. y S. Koyama (2003): Taxa de juros e concentração bancária no Brasil, textos para discusión, $\mathrm{N}^{\circ} 62$, Brasilia, Banco Central de Brasil, febrero.

Vasconcelos, M. R., J. R. Fucidji y otros (2004): O todo e as partes: uma análise da desigualdade de crédito entre os estados brasileiros e os determinantes do crédito bancário com a aplicação de dados em painel, Economia e sociedade, vol. 13, № 1, Campinas, Universidad Estadual de Campinas, enero-junio.

Vilhena, F. y J. Sicsú (2006): Mapeamento da produtividade do trabalho nos bancos brasileiros, en M. Crocco y F.G. Jayme Jr., Moeda e território: uma interpretação da dinâmica regional brasileira, Belo Horizonte, Autêntica.

Wooldridge, J. M. (2002): Econometric Analysis of Cross Section and Panel Data, Cambridge, Massachusetts, The MIт Press. 